\title{
Respiratory Acid-Base Disorders and Related Risk Factors in Critically IIl Patients
}

\author{
Bander A. Musleh ${ }^{1}$, Mohammed Hassan bakri ${ }^{2}$, Mervat A. Abd-ElAziz ${ }^{3}$ \& Mogedda M. Mehany ${ }^{4}$. \\ 1. Clinical Nurse Specialist in National Oncology Center Sana'a, Yemen. \\ 2. Professor of Anesthesia and Intensive Care Unit, Faculty of Medicine, Assiut University, Egypt. \\ 3. Assistant Professor of Critical Care And Emergency Nursing, Faculty of Nursing, Assiut University, Egypt . \\ 4. Assistant Professor of Critical Care and Emergency Nursing, Faculty of Nursing, Assiut University, Egypt .
}

\begin{abstract}
Background: Respiratory acid-base disorders are commonly seen in the critical care setting and can occur independently or coexist with metabolic acid-base disorders. Aim of the study: To explore the pattern of respiratory acid-base disorders and related risk factors in critically ill patients. Design: the descriptive design was utilized in this study. Setting: This study was carried out in the Trauma and general Intensive Care Unit at Assiut university hospital. Sample: fifty patients admitted to trauma and general Intensive Care Unit. Tools: Four tools were used in this study, patient assessment tool, APACHE II tool, Acid-base parameters assessment tool, and Risk factors assessment tool. Result: A total of 50 patients most of them were male with a mean age of $40.37 \pm 13.86$ in the survivors versus $47.75 \pm 11.86$ in non-survivor. APACHE II score was significant in non-survivor group confirmed by $(\mathrm{P}=0.000),(\mathrm{P}=0.003)$ respectively.The incidences of respiratory alkalosis $(52 \%)$, respiratory acidosis $(24 \%)$ were higher in the survivor group. The significant risk factor was iatrogenic(drugs, mechanical ventillation). Conclusion: Respiratory acid-base disorders are common in critically ill patients mainly respiratory alkalosis and the major related risk factor was an iatrogenic.
\end{abstract}

\section{Keywords: Acid-base, critically ill patients \& Risk factors.}

\section{Introduction}

Respiratory acid-base disorders are commonly seen in the critical care setting and can occur independently or coexist with metabolic acid-base disorders. Evaluation of respiratory acid-base disorders can be relatively straightforward in patients with an isolated primary respiratory acidosis or alkalosis, or more complicated when superimposed metabolic acid-base disorders are present. (Kollef et al., 2018).

Respiratory acid-base disorders result from an imbalance

between the rate of $\mathrm{CO} 2$ generation in body tissues and the rate of $\mathrm{CO} 2$ elimination by the lungs. Respiratory acid-base disorders cannot be corrected, even temporarily, by the carbonic acid-bicarbonate buffer system. If the rate of $\mathrm{CO} 2$ generation exceeds the rate of $\mathrm{CO} 2$ removal, respiratory acidosis develops. If the rate of $\mathrm{CO} 2$ elimination exceeds the rate of $\mathrm{CO} 2$ generation, respiratory alkalosis develops. (Martini et al., 2018).

Respiratory acidosis and alkalosis occur as a result of respiratory disturbances. A respiratory disturbance alters the carbonic acid level in the ECF. It is reflected in the $\mathrm{PaCO} 2$ level of an $\mathrm{ABG}$. Compensation for a respiratory disturbance occurs when the lungs attempt to either retain or eliminate $\mathrm{PaCO} 2$ from the body or when the kidneys attempt to restore balance through the conservation, formation, or excretion of bicarbonate (HCO3). (Taylor et al., 2011)

Respiratory alkalosis is the most common acid-base disorder in critical illness because multiple psychological and pathophysiological mechanisms can stimulate respiration. Hypocapnia is significantly correlated with adverse outcome in a variety of critical illnesses. However, in contrast to respiratory acidosis, in which $\mathrm{pH}$ can decrease markedly, it is unusual for respiratory alkalosis to cause a $\mathrm{pH}$ greater than 7.6, except at extremes of altitude. (Ronco et al., 2019)

Disorders of respiratory acid-base balance can lead to severe complications in many disease states, and occasionally the abnormality may be so severe as to become a life-threatening risk factor. The process of analysis and monitoring of arterial blood gas (ABG) is an essential part of diagnosing and managing the oxygenation status and acid-base balance of the highrisk patients, as well as in the care of critically ill patients in the Intensive Care Unit. (Sood et al., 2010).

Acute and chronic illness, trauma, and certain therapeutic interventions may place a patient at high risk for respiratory acid-base imbalances. Such imbalances can seriously compromise the patient's health status and may prove life threatening. The nursing assessment is directed toward the following: Identifying patients at high risk for acid-base 
imbalances, determining that a specific imbalance is present and identifying the nature of the imbalance along with its severity, etiology, and defining characteristics or assessment findings, determining the plan of care, including the appropriate nursing diagnoses or collaborative problems, followed by the identification of specific outcomes, associated interventions, and the evaluation of the effectiveness of the plan of care. (Taylor et al., 2011)

\section{Significance of the study}

Respiratory acid-base disorders are frequent and potentially dangerous complications in the intensive care unit. The incidence of respiratory acid-base disorders may be varied depending on the different underlying diseases and comorbidities. The presence of these disorders does not only signal severe underlying pathophysiology but also is a significant marker of adverse outcomes. The recognition of respiratory acid-base disorders is important from both a diagnostic and therapeutic perspective, emphasizing the role of blood gas evaluation in critical care. (Hu et al., 2017)

Limited data exist respiratory acid-base disorders and related risk factors in critically ill patients admitted to the ICU at Assiut university hospital. So, we conducted this study to describe the trend of respiratory acid-base disorders and related risk factors during hospitalization and across different categories of ICUs.

Aims of the study

To explore the pattern of respiratory acid-base disorders and related risk factors in critically ill patients.

\section{Research Questions}

The study will be directed to answer the following research questions.

1. What are the common types of respiratory acidbase disorders for critically ill patients in intensive care units?

2. What are the risk factors related to respiratory acid-base disorders for critically ill patients in intensive care units?

\section{Patients \& Methods}

\section{Research design}

The descriptive research design was utilized to fulfill the aim of this study.

\section{Setting}

This study was carried out in the Trauma Intensive Care Unit (6 beds) and general Intensive Care Unit (12 beds) Assiut University Hospital.

\section{Sample}

A convenient sample of adult male and female critically ill patients admitted consecutively to the above-mentioned settings of ICUs, between October 2018, and June 2019.

\section{Inclusion criteria}

1. Patients aged between 18 and 60 years old

2. Both sex

3. Patients newly admitted to the ICU during the study period not exceeding 24 hours were included into the study.

\section{Exclusion criteria}

1. Patients without arterial blood gases and laboratory variables needed for the acid-base evaluation proposed were excluded.

2. Patients who transferred out of critical care area within 24 hours of arrival.

\section{Tools of the study}

Data pertinent to the study were collected, utilizing the following tools

\section{Tool one: Patient Assessment Tool}

This tool was developed by the researcher after reviewing the relevant literature to assess the patient's demographic data and health-relevant data is comprised of the following.

Part I- Demographic \& Clinical Data: included name, sex, age reason for ICU admission, type of admission, place prior to admission, presence of comorbidities, unit of admission, mechanical ventilation requirements.

Part II: Vital signs and Hemodynamic Parameter Assessment Sheet

Vital signs included temperature, heart rate, respiratory rate, blood pressure, mean arterial blood pressure and peripheral capillary oxygen saturation

Tool two: Acute Physiology and Chronic Health Evaluation (APACHE II) APACHE II was developed by (Knaus et al., 1985) to determine the severity of disease and mortality. The APACHE score is probably the most common and best-known validated predictive scoring system in the ICU. The APACHE II is still commonly used as an index of illness severity in critically ill patients admitted to ICU and has been validated in many research and clinical audit purposes. (Nath, 2017). APACHE II is the severity of disease classification system. It uses a point score based upon values of 12 routine physiologic measurements (taken during the first 24 $\mathrm{h}$ after admission), age and previous health status to provide a general measure of severity of the disease. An integer score from 0 to 71 is then computed based on these measurements; higher scores imply a more severe disease and a higher risk of death. (Rapsang \& Shyam, 2014)

Tool three: Acid-base Parameters Assessment Tool

This tool was developed by the researcher after reviewing the relevant literature to meet the need for the acid-base evaluation proposed it consists of the two parts. 


\section{Part I: Arterial Blood Gases Parameters Assessment Sheet}

Acid-base parameters and partial pressures will be calculated on arterial blood gases result. Analysis of the $\mathrm{ABG}$ included $\mathrm{pH}$ values, the partial pressure of arterial carbon dioxide $(\mathrm{PaCO} 2)$, the partial pressure of the arterial oxygen $(\mathrm{PaO} 2)$, bicarbonate ( $\mathrm{HCO} 3)$, base excess $\left(\mathrm{BE}_{\mathrm{Ecf}}\right)$, Oxygen Saturation $(\mathrm{SaO} 2)$ and lactate.

\section{Part II: Laboratory Investigations Assessment Sheet}

Laboratory variables needed for the acid-base evaluation proposed like Serum electrolytes including sodium $(\mathrm{Na})$, potassium $(\mathrm{K})$, magnesium $\left(\mathrm{Mg}^{2+}\right)$, calcium $(\mathrm{Ca})$, kidney and liver function tests, white blood cells, Hemoglobin, hematocrit and glucose (Glu).

\section{Tool four: Risk Factors Assessment Tool}

A risk factor assessment tool was specifically designed by the researcher after reviewing the literature with respect to risk factors of respiratory acid-base disorders for critically ill patients in an intensive care unit Patients were evaluated for risk factors of acid-base imbalance by using a risk factor checklist sheet, where each factor was rated as 'present' or 'absent' depending on its presence or absence at the time of development of acid-base imbalance.

\section{Methods}

The study was executed on three phases; Preparatory phase, implementation phase, and evaluation phase.

\section{Preparatory phase}

- Seeking official and non-official permission to conduct the study was obtained by the researcher from the head ICUs units after an explanation of the aim and nature of the study.

- Construction for data collection tools after extensive literature of review.

- Content validity: the tools were tested for content related validity by a jury of 3 specialists in the field of critical care nursing and critical care medicine from Assiut university then the tools were designed in their final format and tested for reliability using internal consistency for all of the tools which were measured using Cronbach's test.

- Pilot study: It was conducted on $10 \%$ of sample in selected setting to evaluate the applicability and clearly of tools, the reliability was tested for tool one: "patient's assessment tool", tool two: " Acid-base parameters assessment tool "and tool three: "risk factors assessment tool" by using Cronbach's alpha (tau-equivalent reliability) coefficient $\quad(r=0.750,0.749$ and 0.711 respectively) which its internal consistency "acceptable", then it was modified according to the result of pilot study.

- Ethical consideration:

- The research proposal was approved from the Ethical committee of the Faculty

- There was no risk of study subjects during the application of the study.

- The study followed common ethical principles in clinical research.

- verbal consent was obtained from patients or guidance that participated in the study, after explaining the nature and the purpose of the study.

- Confidentiality and anonymity were assured.

- Patients had the right to refuse to participate and or withdraw from the study without any rationale at any time.

- The patient was assured that the data of this research was not be reused without second permission

\section{Implementation phase}

- Data were collected from adult critically ill patients managed in intensive care units at Assiut university hospital in nine months between October 10, 2018, and June 30, 2019. The purpose of the study was explained to all conscious patients and the relatives of comatose patients prior to data collection.

- Once the permission was granted to proceed with the proposed study, the researcher's proposal was submitted to the research committee in Assuit University, the name of the patients who have admitted to each unit and who met the criteria was obtained from the responsible nurse in each unit.

- On admission, demographic data age, gender were recorded. Medical and clinical data including causes of ICU admission, type of admission, place prior to admission, past history, presence of comorbidities. Vasopressor used, fluid management, renal replacement requirements, mechanical ventilation requirements, clinical outcomes, and Current medication, were also recorded from the patient's sheet using tool 1 (part I\&II). This was done by asking and reviewing the patient's medical admission sheet.

- APACHE II score was calculated based on the worst values recorded during the first $24 \mathrm{~h}$ of admission. The online APACHE II Calculator (Acute physiology and chronic health evaluation was used to calculate the corresponding score for each patient.

- To fulfill the parameters of acid-base hemostasis or imbalance blood gas samples were collected in a heparin syringe at the time 
of admission and arterial blood gas analyzer. Blood gas analysis included blood $\mathrm{pH}$, partial pressures of carbon dioxide $(\mathrm{PaCO} 2)$, partial pressures of oxygen $(\mathrm{PaO} 2)$, bicarbonate value (HCO3) and base excess of extracellular fluid (BEecf), and lactate were measured with a blood gas analyzer using a Rapid Lab Blood Gas Analyzer (GEM Premier 3000, USA).

- Acid-base homeostasis or imbalance was judged according to the sample taken upon arrival by taking into consideration the expected compensatory response. A $\mathrm{pH}<7.35$ combining with the increase of partial pressure of arterial carbon dioxide (PaCO2) or decrease of bicarbonate is defined as respiratory or metabolic acidosis respectively. A $\mathrm{pH}>7.45$ combining with a decrease of $\mathrm{PaCO} 2$ or increase of $\mathrm{HCO} 3$ - is defined as respiratory or metabolic alkalosis respectively.

- If a primary acidosis or alkalosis is present, the expected degree of compensation can be predicted using the following equations.

\section{Respiratory acid base disorder}

- If measured PCO2 is less than expected PCO2 then respiratory alkalosis is present.

- If measured PCO2 is greater than expected $\mathrm{PCO} 2$ then respiratory acidosis is present.

- Respiratory Acidosis: Plasma HCO3 will increase by $1 \mathrm{meq} / \mathrm{L}$ for each $10 \mathrm{~mm} \mathrm{Hg}$ increase $\mathrm{PCO} 2$ in acute cases and $4 \mathrm{meq} / \mathrm{L}$ in chronic cases.

- Respiratory Alkalosis: Plasma $\mathrm{HCO} 3$ will increase by $2 \mathrm{meq} / \mathrm{L}$ for each $10 \mathrm{~mm} \mathrm{Hg}$ decrease PCO2 in acute cases and 4 meq / $\mathrm{L}$ in chronic cases.

- Samples of separated plasma were analyzed for concentrations of sodium $(\mathrm{Na})$, potassium $(\mathrm{K})$, calcium (Ca),magnesium (Mg2+), albumin (Alb), plasma creatinine and blood urea nitrogen (BUN) by a fully automated analyzer (Dimension RxL Max; Siemens Healthcare Diagnostics, U.S.A.)

- Patients was evaluated for risk factors of acidbase imbalance by using a risk factor checklist sheet, where each factor was rated as 'present' or 'absent' depending on its presence or absence at the time of development of acid-base imbalance.

- All enrolled patients were followed during their ICU stay until discharge or death, and the outcome was recorded as survivors or nonsurvivors.

\section{Evolution phase}

- Finally, the researcher assessed the studied patients in previous mentioned setting for ICUs discharge criteria by recording the following:

- Transferred to another unite.

- Patient dies (death).

\section{Data analysis}

The statistical analysis was carried out using SPSS version 20 software. The collected data were tabulated and analyzed by using frequency distribution, the percentage for qualitative variables. Mean and standard deviation for quantitative variables A P-value $<0.05$ was considered indicating statistical significance. The chi-square test and ANOVA test are used to determine significance for the non-parametric variable. 


\section{Results}

Table (1): Baseline Demographic and clinical data of the critically ill patients and comparisons between the ICU survivors and non-survivors. (No. $=50)$

\begin{tabular}{|c|c|c|c|c|c|c|c|}
\hline \multirow[t]{2}{*}{ Personal data } & \multicolumn{2}{|c|}{ All $(n=50)$} & \multicolumn{2}{|c|}{$\begin{array}{l}\text { Survivors } \\
(\mathrm{n}=38)\end{array}$} & \multicolumn{2}{|c|}{$\begin{array}{c}\text { Non-survivors } \\
(n=12)\end{array}$} & \multirow[t]{2}{*}{ P-value } \\
\hline & No. & $\%$ & No. & $\%$ & No. & $\%$ & \\
\hline \multicolumn{8}{|l|}{ Sex } \\
\hline Male & 33 & 66 & 26 & 68.4 & 7 & 58.3 & \multirow{2}{*}{0.728} \\
\hline Female & 17 & 34 & 12 & 31.6 & 5 & 41.7 & \\
\hline \multicolumn{8}{|l|}{ Age: (years) } \\
\hline$($ Mean \pm SD) & & & \multicolumn{2}{|c|}{$40.37 \pm 13.86$} & \multicolumn{2}{|c|}{$47.75 \pm 11.86$} & 0.103 \\
\hline \multicolumn{8}{|l|}{ Unit of admission } \\
\hline Trauma ICU & 19 & 38 & 16 & 42.1 & 3 & 25 & \multirow{2}{*}{0.501} \\
\hline General ICU & 31 & 62 & 22 & 57.9 & 9 & 75 & \\
\hline \multicolumn{8}{|l|}{ Reason of ICU admission } \\
\hline Respiratory disorders & 17 & 34 & 10 & 26.3 & 7 & 58.3 & 0.077 \\
\hline Trauma & 16 & 32 & 15 & 39.5 & 1 & 8.3 & 0.074 \\
\hline Sepsis/ infection & 3 & 6 & 3 & 7.9 & 0 & 0.0 & 1.000 \\
\hline Post-operative & 11 & 22 & 8 & 21.1 & 3 & 25.0 & 1.000 \\
\hline Post cardiac arrest & 3 & 6 & 2 & 5.3 & 1 & 8.3 & 1.000 \\
\hline \multicolumn{8}{|l|}{ Admission type } \\
\hline Medical & 38 & 76 & 30 & 78.9 & 8 & 66.7 & \multirow{3}{*}{0.275} \\
\hline Elective surgery & 6 & 12 & 5 & 13.2 & 1 & 8.3 & \\
\hline Emergency surgery & 6 & 12 & 3 & 7.9 & 3 & 25.0 & \\
\hline \multicolumn{8}{|c|}{ Location before ICU admission } \\
\hline Ward & 7 & 14 & 5 & 13.2 & 2 & 16.7 & \multirow{4}{*}{0.692} \\
\hline Emergency & 29 & 58 & 23 & 60.5 & 6 & 50.0 & \\
\hline Operation theater & 12 & 24 & 8 & 21.1 & 4 & 33.3 & \\
\hline Another hospital & 2 & 4 & 2 & 5.3 & 0 & 0.0 & \\
\hline
\end{tabular}

Table (2): Clinical data of the critically ill patients in relation to mechanical ventilation and comorbididty and comparisons between the ICU survivors and non-survivors. (No. =50).

\begin{tabular}{|c|c|c|c|c|c|c|c|c|c|}
\hline \multirow{3}{*}{ Clinical data } & \multicolumn{4}{|c|}{$\begin{array}{l}\text { Survivors } \\
(\mathrm{n}=\mathbf{3 8})\end{array}$} & \multicolumn{4}{|c|}{$\begin{array}{c}\text { Non-survivors } \\
\quad(n=12)\end{array}$} & \multirow{3}{*}{ P-value } \\
\hline & \multicolumn{2}{|c|}{ Yes } & \multicolumn{2}{|c|}{ No } & \multicolumn{2}{|c|}{ Yes } & \multicolumn{2}{|c|}{ No } & \\
\hline & No. & $\%$ & No. & $\%$ & No. & $\%$ & No. & $\%$ & \\
\hline Mechanical ventilation & 25 & 65.8 & 13 & 34.2 & 11 & 91.7 & 1 & 8.3 & 0.140 \\
\hline \multicolumn{10}{|l|}{ Comorbidity } \\
\hline Neurological disease & 4 & 10.5 & 34 & 89.5 & 3 & 25.0 & 9 & 75.0 & 0.337 \\
\hline Liver disease & 1 & 2.6 & 37 & 97.4 & 1 & 8.3 & 11 & 91.7 & 0.426 \\
\hline Renal disease & 0 & 0.0 & 38 & 100.0 & 1 & 8.3 & 11 & 91.7 & 0.240 \\
\hline Respiratory disease & 4 & 10.5 & 34 & 89.5 & 3 & 25.0 & 9 & 75.0 & 0.337 \\
\hline Hypertension & 5 & 13.2 & 33 & 86.8 & 3 & 25.0 & 9 & 75.0 & 0.379 \\
\hline Diabetes mellitus & 6 & 15.8 & 32 & 84.2 & 1 & 8.3 & 11 & 91.7 & 1.000 \\
\hline Cancer/ cancer metastasis & 1 & 2.6 & 37 & 97.4 & 2 & 16.7 & 10 & 83.3 & 0.139 \\
\hline
\end{tabular}

* Significant difference at $p$. value $<0.05$.

- Chi square test 
Table (3): Distribution of vital sings\& hemodynamics parameters of the critically ill patients and comparisons between the ICU survivors and non-survivors in respiratory acidosis \& respiratory alkalosis. (No. =50).

\begin{tabular}{|c|c|c|c|c|c|c|}
\hline \multirow{3}{*}{$\begin{array}{c}\text { Vital sings } \\
\text { hemodynamics } \\
\text { parameters }\end{array}$} & \multicolumn{2}{|c|}{ Respiratory acidosis } & \multirow{3}{*}{ P-value } & \multicolumn{2}{|c|}{ Respiratory alkalosis } & \multirow{3}{*}{ P-value } \\
\hline & $\begin{array}{c}\text { Survivors } \\
(\mathrm{n}=12)\end{array}$ & $\begin{array}{c}\text { Non-survivors } \\
(n=7)\end{array}$ & & $\begin{array}{c}\text { Survivors } \\
(\mathrm{n}=26)\end{array}$ & $\begin{array}{c}\text { Non-survivors } \\
(n=5)\end{array}$ & \\
\hline & Mean \pm SD & Mean \pm SD & & Mean \pm SD & Mean \pm SD & \\
\hline Temperature & $37.17 \pm 0.63$ & $37.21 \pm 0.80$ & 0.887 & $37.20 \pm 0.78$ & $38.00 \pm 0.44$ & $0.034^{*}$ \\
\hline Heart rate & $104.92 \pm 15.50$ & $98.43 \pm 17.22$ & 0.409 & $108.85 \pm 21.72$ & $122.00 \pm 19.54$ & 0.219 \\
\hline Respiratory rate & $17.83 \pm 7.17$ & $18.29 \pm 3.73$ & 0.879 & $22.88 \pm 6.98$ & $25.80 \pm 5.02$ & 0.383 \\
\hline MAP & $82.25 \pm 9.85$ & $82.00 \pm 15.82$ & 0.966 & $88.00 \pm 18.75$ & $73.80 \pm 24.49$ & 0.150 \\
\hline SPO2 & $88.25 \pm 8.43$ & $93.86 \pm 1.68$ & 0.104 & $94.54 \pm 6.33$ & $94.00 \pm 3.94$ & 0.857 \\
\hline
\end{tabular}

* Significant difference at p. value <0.05. - ANOVA Test MAP: Mean Arterial Pressure, SPO2: oxygen saturation

Table (4): APACHE II score of the critically ill patients and comparisons between the ICU survivors and non-survivors in respiratory acidosis \& respiratory alkalosis. (No. $=50)$.

\begin{tabular}{|c|c|c|c|c|c|c|}
\hline \multirow{3}{*}{ Apache ii score } & \multicolumn{2}{|c|}{ Respiratory acidosis } & \multirow{3}{*}{ P-value } & \multicolumn{2}{|c|}{ Respiratory alkalosis } & \multirow{3}{*}{ P-value } \\
\hline & $\begin{array}{c}\text { Survivors } \\
(n=12)\end{array}$ & $\begin{array}{c}\text { Non-survivors } \\
(n=7)\end{array}$ & & $\begin{array}{c}\text { Survivors } \\
(n=26)\end{array}$ & $\begin{array}{l}\text { Non-survivors } \\
(n=5)\end{array}$ & \\
\hline & Mean \pm SD & Mean \pm SD & & Mean \pm SD & Mean \pm SD & \\
\hline APACHE II & $17.42 \pm 5.00$ & $27.00 \pm 3.83$ & $0.000^{*}$ & $14.23 \pm 4.35$ & $21.40 \pm 4.98$ & $0.003 *$ \\
\hline Predicted Mortality rate & $28.42 \pm 13.53$ & $53.57 \pm 11.80$ & $0.001 *$ & $19.92 \pm 10.70$ & $37.00 \pm 12.55$ & $0.003 *$ \\
\hline
\end{tabular}

* Significant difference at p. value <0.05. - ANOVA Test APACHE II: Acute Physiology And Chronic Health Evaluation II

Table (5): Acid-base variables in arterial blood gases in the critically ill patients. and comparisons between the ICU survivors and non-survivors.for Respiratory acidosis and Respiratory alkalosis. (No. $=50$ )

\begin{tabular}{|c|c|c|c|c|c|c|}
\hline \multirow{3}{*}{$\begin{array}{l}\text { Arterial blood } \\
\text { gases parameter }\end{array}$} & \multicolumn{2}{|c|}{ Respiratory acidosis } & \multirow{3}{*}{ P-value } & \multicolumn{2}{|c|}{ Respiratory alkalosis } & \multirow{3}{*}{ P-value } \\
\hline & $\begin{array}{c}\text { Survivors } \\
(\mathrm{n}=12)\end{array}$ & $\begin{array}{c}\text { Non-survivors } \\
(\mathbf{n}=7)\end{array}$ & & $\begin{array}{c}\text { Survivors } \\
(\mathrm{n}=26)\end{array}$ & $\begin{array}{c}\text { Non-survivors } \\
(n=5)\end{array}$ & \\
\hline & Mean \pm SD & Mean \pm SD & & Mean \pm SD & Mean \pm SD & \\
\hline PH & $7.33 \pm 0.05$ & $7.26 \pm 0.08$ & $0.041 *$ & $7.48 \pm 0.03$ & $7.48 \pm 0.02$ & 0.661 \\
\hline $\mathrm{PaCo} 2$ & $61.83 \pm 10.91$ & $62.14 \pm 15.94$ & 0.960 & $25.62 \pm 6.51$ & $27.80 \pm 5.89$ & 0.492 \\
\hline $\mathrm{PaO2}$ & $89.25 \pm 55.73$ & $77.57 \pm 23.19$ & 0.607 & $94.96 \pm 50.06$ & $106.60 \pm 75.11$ & 0.663 \\
\hline $\mathrm{HCO3}$ & $32.47 \pm 6.88$ & $28.57 \pm 3.62$ & 0.186 & $19.34 \pm 5.37$ & $20.78 \pm 3.89$ & 0.574 \\
\hline BE & $6.65 \pm 7.22$ & $0.20 \pm 3.87$ & $0.044 *$ & $-4.53 \pm 4.68$ & $-2.60 \pm 3.71$ & 0.393 \\
\hline FiO2 & $45.42 \pm 13.39$ & $49.29 \pm 12.05$ & 0.538 & $40.88 \pm 10.98$ & $49.20 \pm 20.99$ & 0.195 \\
\hline $\mathrm{SaO}_{2}$ & $87.73 \pm 15.23$ & $89.11 \pm 7.21$ & 0.826 & $95.05 \pm 5.46$ & $95.60 \pm 4.04$ & 0.833 \\
\hline Lactate & $1.78 \pm 0.90$ & $1.36 \pm 0.76$ & 0.307 & $1.81 \pm 1.42$ & $2.16 \pm 1.48$ & 0.617 \\
\hline
\end{tabular}

* Significant difference at p. value $<0.05$. - ANOVA Test PaCo2: partial pressure of carbon dioxide, PaO2: partial pressure of oxygen, HCO3:Bicarbonate BE: Base excess, FiO2: Fraction of inspired oxygen, $\mathrm{SaO}_{2}$ : Oxygen saturation.

Table (6): Distribution of laboratory investigation in the critically ill patients and comparisons between the ICU survivors and non-survivors.for Respiratory acidosis and Respiratory alkalosis. (No. $=\mathbf{5 0}$ ).

\begin{tabular}{|c|c|c|c|c|c|c|}
\hline \multirow{3}{*}{$\begin{array}{c}\text { Laboratory } \\
\text { investigation }\end{array}$} & \multicolumn{2}{|c|}{ Respiratory acidosis } & \multirow{3}{*}{ P-value } & \multicolumn{2}{|c|}{ Respiratory alkalosis } & \multirow{3}{*}{ P-value } \\
\hline & $\begin{array}{c}\text { Survivors } \\
(\mathrm{n}=12)\end{array}$ & $\begin{array}{c}\text { Non-survivors } \\
(n=7)\end{array}$ & & $\begin{array}{c}\text { Survivors } \\
(\mathrm{n}=26)\end{array}$ & $\begin{array}{c}\text { Non-survivors } \\
(n=5)\end{array}$ & \\
\hline & Mean \pm SD & Mean \pm SD & & Mean \pm SD & Mean \pm SD & \\
\hline WBC & $10.19 \pm 4.61$ & $11.99 \pm 10.25$ & 0.603 & $14.57 \pm 6.40$ & $16.12 \pm 2.65$ & 0.601 \\
\hline Hemoglobin & $11.78 \pm 2.36$ & $12.51 \pm 2.34$ & 0.522 & $11.39 \pm 3.45$ & $12.02 \pm 2.48$ & 0.702 \\
\hline Sodium & $138.26 \pm 3.69$ & $138.09 \pm 8.68$ & 0.952 & $136.21 \pm 9.53$ & $136.80 \pm 6.61$ & 0.897 \\
\hline Potassium & $4.17 \pm 1.16$ & $4.17 \pm 1.15$ & 0.993 & $3.93 \pm 0.53$ & $4.18 \pm 0.72$ & 0.377 \\
\hline Calcium & $7.63 \pm 1.22$ & $7.79 \pm 0.68$ & 0.766 & $8.08 \pm 0.56$ & $7.62 \pm 0.75$ & 0.119 \\
\hline Blood sugar & $162.17 \pm 61.05$ & $176.14 \pm 34.78$ & 0.588 & $211.65 \pm 99.42$ & $150.20 \pm 26.73$ & 0.186 \\
\hline BUN & $8.82 \pm 5.02$ & $14.86 \pm 5.37$ & $0.024 *$ & $6.90 \pm 2.82$ & $13.26 \pm 11.14$ & $0.013 *$ \\
\hline Creatinine & $84.50 \pm 38.86$ & $130.29 \pm 52.32$ & $0.043^{*}$ & $77.92 \pm 41.68$ & $84.80 \pm 51.98$ & 0.747 \\
\hline
\end{tabular}

* Significant difference at p. value <0.05. - ANOVA Test $\quad$ WBC: White blood cell, BUN blood urea nitrogen 


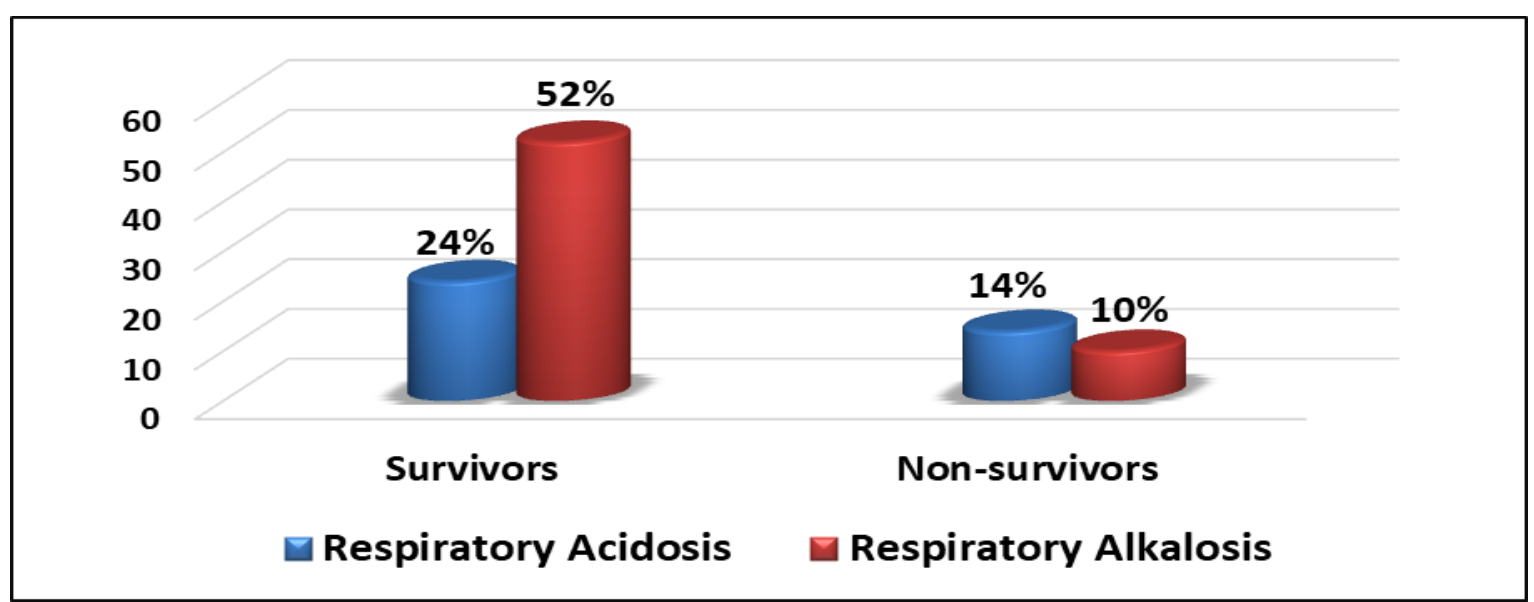

Figure (1): Frequency and percentages distribution of respiratory acid base disorders in the critically ill patients and comparisons between the ICU survivors and non-survivors. (No. $=50)$.

Table (7): Distribution of risk factors for respiratory alkalosis in the critically ill patients and comparisons between the ICU survivors and non-survivors. (No. =31).

\begin{tabular}{|c|c|c|c|c|c|c|c|c|c|}
\hline \multirow{3}{*}{$\begin{array}{c}\text { Risk factors of respiratory } \\
\text { alkalosis }\end{array}$} & \multicolumn{4}{|c|}{$\begin{array}{c}\text { Survivors } \\
(n=26)\end{array}$} & \multicolumn{4}{|c|}{$\begin{array}{c}\text { Non-survivors } \\
(\mathbf{n}=\mathbf{5})\end{array}$} & \multirow{3}{*}{ P-value } \\
\hline & \multicolumn{2}{|c|}{ Yes } & \multicolumn{2}{|c|}{ No } & \multicolumn{2}{|c|}{ Yes } & \multicolumn{2}{|c|}{ No } & \\
\hline & No. & $\%$ & No. & $\%$ & No. & $\%$ & No. & $\%$ & \\
\hline Iatrogenic factors & 21 & 80.8 & 5 & 19.2 & 4 & 80.0 & 1 & 20.0 & 1.000 \\
\hline Pulmonary disorders & 19 & 73.1 & 7 & 26.9 & 4 & 80.0 & 1 & 20.0 & 1.000 \\
\hline Chest trauma & 11 & 42.3 & 15 & 57.7 & 0 & 0.0 & 5 & 100.0 & 0.133 \\
\hline Neurology disorders & 11 & 42.3 & 15 & 57.7 & 0 & 0.0 & 5 & 100.0 & 0.133 \\
\hline Electrolyte disorders & 8 & 30.8 & 18 & 69.2 & 1 & 20.0 & 4 & 80.0 & 1.000 \\
\hline Infection & 7 & 26.9 & 19 & 73.1 & 3 & 60.0 & 2 & 40.0 & 0.296 \\
\hline Head trauma & 5 & 19.2 & 21 & 80.8 & 1 & 20.0 & 4 & 80.0 & 1.000 \\
\hline
\end{tabular}

* Significant difference at $p$. value $<0.05$.

- Chi square test

*Iatrogenic was defined as an unintended injury or harm to a patient resulting from health care management rather than a disease process.(Medication \&mechanical ventilation)

Table (8): Distribution of Risk factors for respiratory acidosis in the critically ill patients and comparisons between the ICU survivors and non-survivors. . (No. =19).

\begin{tabular}{|c|c|c|c|c|c|c|c|c|c|}
\hline \multirow{3}{*}{$\begin{array}{l}\text { Risk factors of respiratory } \\
\text { acidosis }\end{array}$} & \multicolumn{4}{|c|}{ Survivors $(n=12)$} & \multicolumn{4}{|c|}{ Non-survivors $(n=7)$} & \multirow{3}{*}{ P-value } \\
\hline & \multicolumn{2}{|c|}{ Yes } & \multicolumn{2}{|c|}{ No } & \multicolumn{2}{|c|}{ Yes } & \multicolumn{2}{|c|}{ No } & \\
\hline & No. & $\%$ & No. & $\%$ & No. & $\%$ & No. & $\%$ & \\
\hline Iatrogenic factors & 12 & 100.0 & 0 & 0.0 & 7 & 100.0 & 0 & 0.0 & $\overline{--}$ \\
\hline Pulmonary disorders & 9 & 75.0 & 3 & 25.0 & 5 & 71.4 & 2 & 28.6 & 1.000 \\
\hline Electrolyte disorders & 6 & 50.0 & 6 & 50.0 & 3 & 42.9 & 4 & 57.1 & 1.000 \\
\hline Infection & 3 & 25.0 & 9 & 75.0 & 4 & 57.1 & 3 & 42.9 & 0.326 \\
\hline Neurology disorders & 2 & 16.7 & 10 & 83.3 & 1 & 14.3 & 6 & 85.7 & 1.000 \\
\hline Chest trauma & 1 & 8.3 & 11 & 91.7 & 0 & 0.0 & 7 & 100.0 & 1.000 \\
\hline Cardiovascular disorders & 1 & 8.3 & 11 & 91.7 & 2 & 28.6 & 5 & 71.4 & 0.523 \\
\hline
\end{tabular}

* Significant difference at $p$. value $<0.05$.

Table (1): Shows distribution of the study sample according to demographic and clinical data, A total of 50 patients most of them were male(33) was more compared to the females(17) there was no significant difference between the survivor and the non-survivor group regarding the gender. A mean age of $40.37 \pm$ 13.86 in the survivors versus $47.75 \pm 11.86$ in nonsurvivor. it shows that about $(50 \%)$ of the sample admitted to General ICU. The categories for reason of ICU admission were classified into respiratory 
disorders ( $\mathrm{N}=17,34 \%)$; Trauma $(\mathrm{N}=16,34 \%)$; Sepsis $(\mathrm{N}=3,6 \%)$; Post-operative ( $\mathrm{N}=11,22 \%)$; Post cardiac arrest $(\mathrm{N}=3,6 \%)$. Trauma was the predominant Reason for ICU admission.

Table (2): Show underlying diseases indicate both mechanical ventilation and comorbid disease identified in the patients' medical record. Regarding to mechanical ventilation and the co-morbidities, there was no statistically significant difference between the survivor and the non-survivor group.

Table (3): Show there were statistically significant difference increased in the non-survivor group than the survivor group regarding to temperature in respiratory alkalosis. The mean of temperature in the non- survivor group $(38.00 \pm 0.44)$ was comparatively higher than the survivor group $37.20 \pm$ $0.78),(p=0.034)$. As regards to heart rate, espiratory rate, mean arterial pressure, and peripheral capillary oxygen saturation, there were no statistically significant difference between the survivor and the non-survivor group in both respiratory acidosis and respiratory alkalosis.

Table (4): Show there were statistically significant difference increased in the non-survivor group than the survivor group regarding APACHE II score in in both respiratory acidosis and respiratory alkalosis confirmed by $(\mathrm{P}=0.000)$ and $(\mathrm{P}=0.003)$ respectively. Also, I noticed there were statistically significant difference increased in the non-survivor group than the survivor group regarding predicted icu mortality rate in in both respiratory acidosis and respiratory alkalosis confirmed by $(\mathrm{P}=0.001)$ and $(\mathrm{P}$ $=0.003$ ) respectively.

Table (5): On analyzing the acid-base values, there was a clinically significant difference in serum $\mathrm{HCO} 3$ (bicarbonate) and $\mathrm{pH}$ between the survivor and the non-survivor groups in respiratory acidosis which was also confirmed by statistical significance (pH $\mathrm{p}=0.041) \quad(\mathrm{HCO} 3 \mathrm{p}=0.044)$. in respiratory alkalosis no statistical significance regarding acidbase values.

Table (6): Show there were no statistically significant difference between the survivor and the non-survivor group in both respiratory acidosis and respiratory alkalosis regarding to WBC (white blood cell), hemoglobin, electrolyte values and blood sugar. This could be attributed be to the small sample size. On contaray, there were statistically significant difference increased in the non-survivor group than the survivor group in blood urea nitrogen and creatinine respectively $(\mathrm{P}=0.024)$ and $(\mathrm{P}=0.043)$ in respiratory acidosis. Regarding to blood urea nitrogen and creatinine in respiratory alkalosis, there were statistically significant difference increased in the non-survivor group than the survivor group in blood urea nitrogen $(\mathrm{P}=0.013)$ and no significant difference in creatinine $(\mathrm{P}=0.747)$.

Figure (1): Respiratory acid base disorders were observed in 50 critically ill patients. The incidences of respiratory alkalosis $(52 \%)$ in survivor patients, vs $(10 \%)$ in non survivor .Respiratory acidosis were found in (24\%) of survivor patients vs (14\%) in non survivor. Frequency and percentages are shown in figure-1. respiratory alkalosis occurred more commonly as compared to respiratory acidosis. Death was more commonly observed in cases with respiratory acidosis.

Table (7): Show the risk factors of respiratory alkalosis in critically ill patients, the iatrogenic risk factors was most common which include (drugs and mechanical ventilation $(\mathrm{N}=21,80,8 \%$ in survivor patients vs. $\mathrm{N}=4,80.0 \%$ in non-survivor patients) followed by pulmonary disorders, $(\mathrm{N}=19,73.1 \%$ in survivor patients vs. $\mathrm{N}=4,80.0 \%$ in non-survivor patients) ,chest trauma and neurological disorders respectively $(\mathrm{N}=11,42.3 \%$ in survivor patients vs. $\mathrm{N}=$ $0,0.0 \%$ in non-survivor patients) respectively.

Table (8): Show the risk factors of respiratory acidosis in critically ill patients, the iatrogenic risk factors was most common which include (drugs and mechanical ventilation) $(\mathrm{N}=12,100 \%$ in survivor patients vs. $\mathrm{N}=7,100 \%$ in non-survivor patients) followed by pulmonary disorders and electrolyte imbalance $(\mathrm{N}=9,75.0 \%$ in survivor patients vs. $\mathrm{N}=$ $5,71.4 \%$ in non-survivor patients) electrolyte imbalance ( $\mathrm{N}=6,50.0 \%$ in survivor patients vs. $\mathrm{N}=3$, $42,9 \%$ in non-survivor patients) respectively.

\section{Discussion}

Assessment of acid base status of critically ill patients is an integral component of diagnostic workup of these cases as various acid base disorders are present in such clinical scenarios. However the pattern of respiratory acid base disorders among critically ill patients being managed in acute care facilities is seldom reported.(Ahmad et al., 2015) Our findings have shown that the incidence of respiratory Acid base disorders in such cases.

In the present study, our sample size included fifty patients, most of them were male. There was no significant difference between the survivor and the non-survivor group regarding the gender. Our data shows that about half of the sample admitted to General ICU. Regarding to prior place of ICU admission most patients admitted from the emergency department in both survivors and nonsurvivor patients. The categories for reason of ICU admission were classified into respiratory disorders, Trauma, Sepsis, Post-operative, Post cardiac arrest. Trauma was the predominant Reason for ICU admission among survivor patients. 
In the category of respiratory acid base disorders respiratory alkalosis is, overall, the most common acid-base disorder in ICU patients. more than half of patients presented in critical condition had respiratory alkalosis among survivor patients. The results of the present study agree with An Iranian study, by (Hamdi et al., 2016) who reported the most common acid-base abnormality observed in critically ill patients is respiratory alkalosis with no discrimination between genders. These results also in agreement with Another study conducted by (Praveen et al., 2014) entitled of etiologies and outcomes of various types of acid-base disorders in respiratory intensive care unit. He reported that the most common simple acid-base disorder was respiratory alkalosis.

In respiratory acid base disorder combinations, respiratory alkalosis is more common than respiratory acidosis which reflects that respiratory compensation mechanism is major way leading to acid base disorder. Some iatrogenic risk factors should be considered in addition to body compensatory mechanism. (Ahmad et al., 2015) \& (Song et al., 2012).

In the present study respiratory alkalosis was associated with a case low fatality rate. The same has been observed by (JL Wadhwani et al., 2019) in patients who were critically ill .He reported that post hypercapnic alkalosis is overlooked as a complication of mechanical ventilation in the patient with exacerbation of chronic obstructive pulmonary disease (COPD). Development of post hypercapnic alkalosis was associated with an increased incidence of ventilator dependence and duration of ICU stay but no increase in mortality.

Regarding The risk factors of respiratory alkalosis in critically ill patients There is no single factors which can explain the occurrence of respiratory alkalosis. Rather, it is an interplay of factors that increase the probability of its occurrence. The findings of the present study showed several risk factors for respiratory alkalosis. The iatrogenic risk factors was most common which include (drugs and mechanical ventilation). Our finding study in the same line with (Shahriar, 2019) who reported common Iatrogenic factors of respiratory alkalosis include medications like progesterone, methylxanthines (e.g., theophylline), salicylates, catecholamine's and nicotine as well as excessive minute ventilation provided by mechanical ventilation.

The least common respiratory acid base disorders observed in our study was respiratory acidosis. less than half of patients presented in critical condition has respiratory acidosis. Our findings can be matched with studies by (Sasirekha, 2008). According to the study of one hundred patients, simple respiratory acidosis is the least common.

Regarding the risk factors of respiratory acidosis, our study has shown that a substantial proportion of critically Ill patients admitted to ICU had iatrogenic events. We identified the major risk factors of iatrogenic events as medication and mechanical ventilation. The results of the present study agree with (Alonso et al., 2015) who reported the patients with alveolar hypoventilation taking CNS depressants (Sedation or analgesia) alone or in combination are at greater risk of respiratory acidosis.

In addition, this results supported by (Ogino et al., 2016) who stated that the most common iatrogenic cause of hypoventilation in the ICU is medication overdose, including narcotics, benzodiazepines, and other anxiolytics and sleep aides. In the same line Our finding study in agreement with (Ahmad et al., 2015) \& (Ligi et al., 2008) they documented the use of mechanical ventilation are common iatrogenic factors inducing acid base disorders

The use of different central nervous system depressants (Sedation or analgesia) in critically ill patients is a growing practice drugs, particularly in combination, inhibits the activity of the medullary and bulbopontine respiratory centers, which in turn diminishes the ventilatory response to hypoxia and hypercapnia, and can cause respiratory acidosis .This therapy is not without its complications, most notably respiratory center depression and respiratory acidosis requiring ventilatory support. It is therefore essential to be aware of these complications and identify which patients are at greater risk (Alonso et al., 2015).

\section{Conclusions}

Based on our finding of the current study, it can be concluded that respiratory acid-base disorders are common in critically ill patients presenting at the ICU. Of the respiratory acid-base disorders respiratory alkalosis was more common among Thus, cases. Regarding to major related risk factor the itrogenic risk factor was the comments in both respiraroy alkalosis and respiratory acidosis respectively. These disturbances should be monitored closely, diagnosed early and managed correctly during hospitalization and iatrogenic factors should be avoided.

\section{Recommendation}

1. Respiratory acid-base disorders are extremely common in critically ill patients. They carry increased morbidity and mortality. Therefore, accurate assessment and appropriate therapeutic intervention are necessary to prevent these associated complications and identify which patients are at greater risk. 
2. Reduction of the minute ventilation may require mechanical ventilation to temporarily reverse the alkalosis mainly in situations where hypoxia is a driving factor.

\section{References}

1. Ackley, J., Lawdig, B., \& Makic, M., (2017): Nursing Diagnosis Handbook: An EvidenceBased Guide to Planning Care (11th editi). United States of America: Elsevier Health Sciences.

2. Ahmad, T., Mehmood, A., Malik, T., \& Aamir, M., (2015): Pattern of acid base abnormalities in critically ill patinets. 65(1), 99104.

3. Alonso, T., García, E., Segrelles, G., \& Zamora, E., (2015): spiratory Acidosis Secondary to Drug Therapy. Journal of Chemical Information and Modeling, 51(4), 204-205. https://doi.org/10.1017/CBO9781107415324.004

4. Amalraj, P., Narayanan, A., Balan, S., \& Thomas, M., (2017): Metabolic acidosis in medical intensive care unit with indicators and their prognostic value- A prospective observational study. Asian Journal of Medical Sciences, $\quad 8(3), \quad 60-67$. https://doi.org/10.3126/ajms.v8i3.16500

5. Aseni, P., Orsenigo, S., Storti, E., Pulici, M., \& Arlati, S., (2018): Current concepts of perioperative monitoring in high-risk surgical patients: A review. Patient Safety in Surgery, 13(1), 1-9. https://doi.org/10.1186/s13037-0190213-5

6. Colonel, L., \& Kalam, A., (2016): Simple Algorithm of Arterial Blood Gas Analysis to Ensure Consistent , Correct and Quick Responses! $5(5)$. https://doi.org/10.15406/jaccoa.2016.05.00199

7. Gilbert, S., \& Weiner, D., (2018): National Kidney Foundation Primer on Kidney Diseases (7th editio). China: Elsevier Health Sciences.

8. Hamdi, H., Hassanian-Moghaddam, H., Hamdi, A., \& Zahed, N., (2016): Acid-base disturbances in acute poisoning and their association with survival. Journal of Critical Care, 35, 84-89. https://doi.org/10.1016/j.jcrc.2016.05.003

9. Hu, J., Wang, Y., Chen, R., Zhang, X., Lin, J., Teng, J., \& Ding, X., (2017): Electrolyte and acid-base disturbances in critically ill patients: A retrospective and propensity-matched study. International Journal of Clinical and Experimental Medicine, 10(1), 992-1003.

10.Hu, J., Wang, Y., Geng, X., Chen, R., Xu, X., Zhang, X., Ding, X., (2017): Metabolic acidosis as a risk factor for the development of acute kidney injury and hospital mortality. Experimental and Therapeutic Medicine, 13(5), 2362-2374.

11.Ian Shane, A., Robert, W., Arthur, K., Patson, M., \& Moses, G., (2014): Acid-Base disorders as predictors of early outcomes in major Trauma in a resource limited setting: An observational prospective study. Pan African Medical Journal, 17, 1-7.

12.JL Wadhwani, Deopujari, K., Jagat, R., \& Shukla, P., (2019): Study of acid-base imbalance in critically ill patients and its outcome in emergency medical ward of Hamidia Hospital: A study from Bhopal. International Journal of Medicine Research, 4(1), 47-50.

13.Kee, J., Paulanka, B., \& Polek, C., (2010): Handbook of fluid, electrolyte, and acid-base imbalances. In Sciences-New York (3rd editio). United States of America: Delmar Cengage Learning.

14.Knaus, W., Draper, E., Wagner, D., \& Zimmerman, J., (1985): APACHE II: A severity of disease classification system. Critical Care Medicine, Vol. 13, pp. 818-829.

15.Kollef, M., Isakow, W., Burks, A., \& Despotovic, V., (2018): THE WASHINGTON MANUAl OF CRITICAL CARE (3rd Editio). China.: Wolters Kluwer.

16.Kraut, J., \& Madias, N., (2018): Re-evaluation of the normal range of serum total $\mathrm{CO} 2$ concentration. Clinical Journal of the American Society of Nephrology, 13(2), 343-347.

17.Leach, R., Moore, K., \& Bell, D., (2016): Oxford Desk Reference: Acute Medicine. Retrieved from https://books.google.com.eg/books?id=1DIRDA AAQBAJ

18.Ligi, I., Arnaud, F., Jouve, E., Tardieu, S., Sambuc, R., \& Simeoni, U. (2008). Iatrogenic events in admitted neonates: a prospective cohort study. The Lancet, 371(9610), 404-410. https://doi.org/10.1016/S0140-6736(08)60204-4

19.Martini, F., Ober, W., Nath, J., Bartholomew, E., \& Petti, K., (2018): Visual Anatomy \& Physiology (3rd editio). United States of America: Pearson Education, Inc.

20.Mount, D., Sayegh, M., \& Singh, A., (2013): Core Concepts in the Disorders of Fluid, Electrolytes and Acid-Base Balance (1st editio). Springer Science.

21.Na, S., Ha, T., Koh, Y., Suh, G., Koh, S., Lim, C., Jeon, K., (2018): Characteristics and clinical outcomes of critically ill cancer patients admitted to Korean intensive care units. Acute and Critical 
Care, 33(3),

https://doi.org/10.4266/acc.20

22.Nath, J., (2017): Research Article. SciFed Obstetrics and Women Healthcare Journal, 1(1), 521-526. 1000003

https://doi.org/10.23959/sfowj-

23.Ogino, H., Nishimura, N., Yamano, Y., Ishikawa, G., Tomishima, Y., Jinta, T., Chohnabayashi, N., (2016): Analysis of the clinical backgrounds of patients who developed respiratory acidosis under high-flow oxygen therapy during emergency transport. Acute Medicine \& Surgery, 3(1), 26-31. https://doi.org/10.1002/ams2.138

24.Praveen, J., Reddy, V., behera, G., Sowjanya, D., Prithvi, B., \& Ramya, G., (2014): Etiologies and Outcomes of various types of Acid-Base Disorders in Respiratory intensive care unit. IOSR Journal of Dental and Medical Sciences, 13(9), 37-43.

25.Rapsang, A., \& Shyam, D., (2014): Scoring systems in the intensive care unit: A compendium. Indian Journal of Critical Care Medicine, 18(4), 220-228. https://doi.org/10.4103/0972-5229.130573

26. Reddi, A., (2018): Fluid, Electrolyte and AcidBase Disorders (2nd editio). United States of America: Springer International Publishing.

27.Ronco, C., Bellomo, R., Kellum, J., \& Ricci, Z., (2019): Critical Care Nephrology, (3rd editio). Retrieved from www.elsevier.com/permissions.

28.Sackner, M., (2018): Arterial blood gas analysis. Medical Times, 95(1), 79-87.

29.Sasirekha, K., (2008): A Study on Acid Base Status among Intensive Medical Care Unit Patients. Madras Medical College, Chennai.

30.Shahriar, A., (2019): Hospital Medicine. Retrieved from Neurology Advisor website: https://www.neurologyadvisor.com/decisionsupport-in-medicine/hospitalmedicine/respiratory-alkalosis/

31.Singh, V., Gupta, P., \& Khatana, S., (2013): Blood gas analysis for bedside diagnosis. National Journal of Maxillofacial Surgery, 4(2), 136. https://doi.org/10.4103/0975-5950.127641

32.Song, Z., Gu, W., Li, H. J., \& Ge, X., (2012): The incidence and types of acid-base imbalance for critically ill patients in emergency. https://doi.org/10.1177/102490791201900103

33.Sood, P., Paul, G., \& Puri, S., (2010): Interpretation of arterial blood gas. Indian Journal of Critical Care Medicine: PeerReviewed, Official Publication of Indian Society of Critical Care Medicine, 14(2), 57-64. https://doi.org/10.4103/0972-5229.68215

34. Taylor, C., Lillis, C., LeMone, P., \& Lynn, P., (2011): Fundamental of Nursing: The Art and Science of Nursing Care (7th editio). https://doi.org/10.1097/00003465-199001000-

00006 